\title{
Mapping of potential neurogenic niche in the human temporal lobe
}

\author{
Mapeamento de potencial nicho neurogênico no lobo temporal humano \\ Adriano Barreto Nogueira
}

\begin{abstract}
Support: Fundação de Amparo à Pesquisa do Estado de São Paulo (FAPESP) (grant \#2010/51634-1) and Conselho Nacional de Desenvolvimento Científico e Tecnológico (CNPq) (grant \#401002/2013-6).

Resumo de Tese de Doutorado apresentada à Faculdade de Medicina da Universidade de São Paulo, São Paulo SP, Brasil.

Correspondence: Adriano Barreto Nogueira; Avenida Dr. Eneas de Carvalho Aguiar, 255, 5²Andar; 05403-900 São Paulo SP, Brasil; E-mail: adriano.nogueira@ hc.fm.usp.br
\end{abstract}

Orientador: Paulo Eurípedes Marchiori

Received 2 June 2014; Received in final form 13 June 2014; Accepted 3 July 2014.

\begin{abstract}
The subgranular zone (SGZ) of the dentate gyrus and the subventricular zone (SVZ) are known neurogenic niches in adult mammals. Nonetheless, the existence of neurogenic niches in adult humans is controversial. We hypothesized that mapping neurogenic niches in the human temporal lobe could clarify this issue. Neurogenic niches and neurogenesis were investigated in 28 temporal lobes via immunostaining for nestin and doublecortin (DCX), respectively. Nestin was observed in a continuous layer formed by the SVZ, the subpial zone of the medial temporal lobe and the SGZ, terminating in the subiculum. In the subiculum, remarkable DCX expression was observed through the principal efferent pathway of the hippocampus to the fimbria. A possible explanation for the results is that the SVZ, the subpial zone of the medial temporal lobe and the SGZ form a unit containing neural stem cells that differentiate into neurons in the subiculum. Curiously, the area previously identified as the human rostral migratory stream may in truth be the fornix, which contains axons that originate in the subiculum. This study suggests that neurogenesis may occur in an orchestrated manner in a broad area of the human temporal lobe.
\end{abstract}

Keywords: neurogenesis, stem cell niche, humans, adult, temporal lobe, limbic system. 